\title{
Discrete Second-Order Sliding Mode Adaptive Controller Based on Characteristic Model for Servo Systems
}

\author{
Zhihong Wang, ${ }^{1}$ Yifei Wu, ${ }^{1}$ Wei Chen, ${ }^{2}$ Xiang Wang, ${ }^{1}$ Jian Guo, ${ }^{1}$ and Qingwei Chen ${ }^{1}$ \\ ${ }^{1}$ School of Automation, NUST, Nanjing 210094, China \\ ${ }^{2}$ Electronic and Mechanical Technology Department, Nanjing Marine Radar Institute, Nanjing 210003, China \\ Correspondence should be addressed to Yifei Wu; wuyifei0911@163.com
}

Received 17 December 2014; Revised 23 February 2015; Accepted 27 February 2015

Academic Editor: Seiichiro Katsura

Copyright (c) 2015 Zhihong Wang et al. This is an open access article distributed under the Creative Commons Attribution License, which permits unrestricted use, distribution, and reproduction in any medium, provided the original work is properly cited.

\begin{abstract}
Considering the varying inertia and load torque in high speed and high accuracy servo systems, a novel discrete second-order sliding mode adaptive controller (DSSMAC) based on characteristic model is proposed, and a command observer is also designed. Firstly, the discrete characteristic model of servo systems is established. Secondly, the recursive least square algorithm is adopted to identify time-varying parameters in characteristic model, and the observer is applied to predict the command value of next sample time. Furthermore, the stability of the closed-loop system and the convergence of the observer are analyzed. The experimental results show that the proposed method not only can adapt to varying inertia and load torque, but also has good disturbance rejection ability and robustness to uncertainties.
\end{abstract}

\section{Introduction}

The growth and development of our modern society is heavily dependent on the development, sustenance, and improvement of control systems. In recent years, there has been an increasing demand for high precision controllers in servo systems which should have fast tracking behavior, good disturbance rejection ability, and robustness under uncertainties. However, to improve the performance of servo systems is a formidable task due to several reasons, such as the variation of system inertia and load torque, the nonlinearities caused by backlash, friction, other uncertain disturbances, and variable unknown command signal. The above factors cannot be predicted beforehand, which makes the problem more challenging.

Design of controllers considering backlash and friction has received a lot of attention. Problems like tracking errors, self-excited vibration, delays, and steady state errors may arise in this situation. A recent survey paper [1] summarized the backlash models and the compensation methods. Different mathematical models have been developed to describe the backlash phenomenon, such as dead-zone model and hysteresis model [1]. Friction modeling and compensation have been studied extensively in the past few decades. Dynamic friction models, mainly including the Dahl model [2] and the LuGre model [3], have been proposed and shown to be more beneficial. The majority of previous studies have addressed either the friction compensation problem or the backlash compensation problem. Very few papers dealt with them together. The control of systems in the presence of backlash and friction was discussed in $[4,5]$. In [4], the neural network model was adopted, and the experiment was carried out under the condition of low velocity and constant inertia and load torque. In [5], fuzzy logic-based algorithm was used to reduce the effect of backlash and friction, and simulation results were presented to show the effectiveness of the controller. In [6], an adaptive fuzzy speed controller based on the backstepping method was designed by considering the existence of parameter variations and load disturbances; experiments indicated that the designed controller performed with better adaptability and robustness compared with the proportion integration (PI) controller. However, parameter adjustment is relatively complex.

According to the above situations, controllers of timevarying servo systems should have fast reaction characteristic and high precision tracking behavior. So an adaptive sliding mode controller is chosen to be applied in the servo system. Focusing on control algorithm, sliding mode control (SMC) 
is a nonlinear control method which is capable of suppressing the influence of model perturbations and external disturbances [7]. The analysis and applications of high-order SMC have become the research hotspot [8-10], especially the second-order SMC owing to its simple structure and easy realization [11-15]. In [11], the second-order SMC was combined with the fuzzy identification to make it converge in a finite period of time without chattering, and the adaptive robust compensation was also employed to improve precision. In [12], high-order sliding mode controller was proposed for PMSM speed control. Nonsingular terminal sliding modes were designed and used to eliminate the chattering and stabilize the system. In [13], a second-order sliding mode controller was designed for output tracking of mobile manipulators to improve the tracking performance and reduce the chattering.

To improve the performance of the controller under conditions of backlash, friction, and variable inertia and load torque, we should find a SMC with good adaptive ability. Our motivation is to find a proper modeling method and an effective control algorithm to follow the command signal with high acceleration and velocity. Moreover, very few researches of servo systems with variable inertia and load torque were carried out. This motivates us to carry out the present work to use a new modeling method called characteristic modeling which is proposed by Wu et al. [16]. The main advantage of characteristic modeling is that the system can be described by a second-order time-varying difference equation, and the model parameters are determined beforehand within a fairly small range, which is beneficial to fast parameter convergence of online identification [16, 17]. And all the uncertainties and nonlinearities can be included in the characteristic model. In addition to modeling method, proper control algorithm is also very important in the presence of uncertainties and nonlinearities. In the following sections, a novel adaptive discrete second-order sliding mode controller based on characteristic model is proposed, and a command observer is adopted to predict command value. In addition to simulations, experimental results show that the proposed method can obtain good performance in servo systems with varying inertia and load torque and has good adaptive ability and robustness.

The remainder of this paper is organized as follows. Section 2 gives the original dynamic model and the characteristic model of the servo system, and the effectiveness of the characteristic model is verified by simulations. In Section 3, a command observer is designed, a discrete second-order sliding mode adaptive controller based on characteristic model is proposed, and the stability of the closed-loop system is analyzed. Section 4 presents the experimental results. Finally, the conclusion is given in Section 5 .

\section{Problem Description and System Modeling}

The characteristic modeling is based on the dynamics characteristics and control performance requirements of the plants, rather than being only based on accurate plant dynamics analysis. For the same input, a plant characteristic model is equivalent to its practical plant in output. In a dynamic process, the output error can be maintained within a permitted range. In the steady state, their outputs are equal. A characteristic model is different from the reduced-order model of a high-order system. It compresses all the information of the high-order model into several characteristic parameters. Above all, the characteristic modeling makes it possible to design a feasible low-order intelligent controller for various complicated plants with nonlinearities and uncertainties.

The nonlinear system is expressed as

$$
\dot{x}(t)=f\left(x, \dot{x}, \ldots, x^{(n)}, u, \dot{u}, \ldots u^{(m)}\right)
$$

Define $x=x_{1}, \dot{x}=x_{2}, \ldots, x^{(n)}=x_{n+1}$ and $u=u_{1}, \dot{u}=$ $u_{2}, \ldots, u^{(m)}=u_{m+1}$; then, (1) can be rewritten as

$$
\dot{x}(t)=f\left(x_{1} \cdots x_{n+1}, u_{1} \cdots u_{m+1}\right) .
$$

The nonlinear system (2) is assumed to be as follows.

(1) The system is a SISO system.

(2) The order of the control input $u(t)$ is 1 .

(3) $f(\cdot)=0$ when all the bounded variables $x_{i}$ and $u_{i}$ are equal to zero.

(4) $f(\cdot)$ is continuous differentiable to all the variables $x_{i}$ and $u_{i}$, and all partial derivatives are bounded.

(5) $|f(x(t+\Delta t), u(t+\Delta t))|-|f(x(t), u(t))|<M \Delta t$, where $\Delta t$ is the sample period and $M$ is a positive constant.

Lemma 1 (see [16]). If system (2) satisfies the above assumptions, the characteristic model of the system can be established by a second-order slow time-varying difference equation as

$$
\begin{aligned}
x(k+1)= & f_{1}(k) x(k)+f_{2}(k) x(k-1) \\
& +g_{0}(k) u(k)+g_{1}(k) u(k-1),
\end{aligned}
$$

where $f_{1}(k), f_{2}(k), g_{0}(k)$, and $g_{1}(k)$ are the time-varying parameters of the model, which can be estimated online. And the parameter range can be determined as $f_{1}(k) \in(1,2]$, $f_{2}(k) \in[-1,0), g_{0}(k) \ll 1$, and $g_{1}(k) \ll 1$.

If system (2) is a minimum phase system, the $g_{1}(k) u(k-1)$ in (3) can be neglected. The characteristic model of the system can be written as

$$
x(k+1)=f_{1}(k) x(k)+f_{2}(k) x(k-1)+g_{0}(k) u(k) .
$$

The research object is a typical servo system driven by gears; when the system is encountered with backlash and friction, the nonlinear component could be described by a continuous differentiable approximate function to make the 


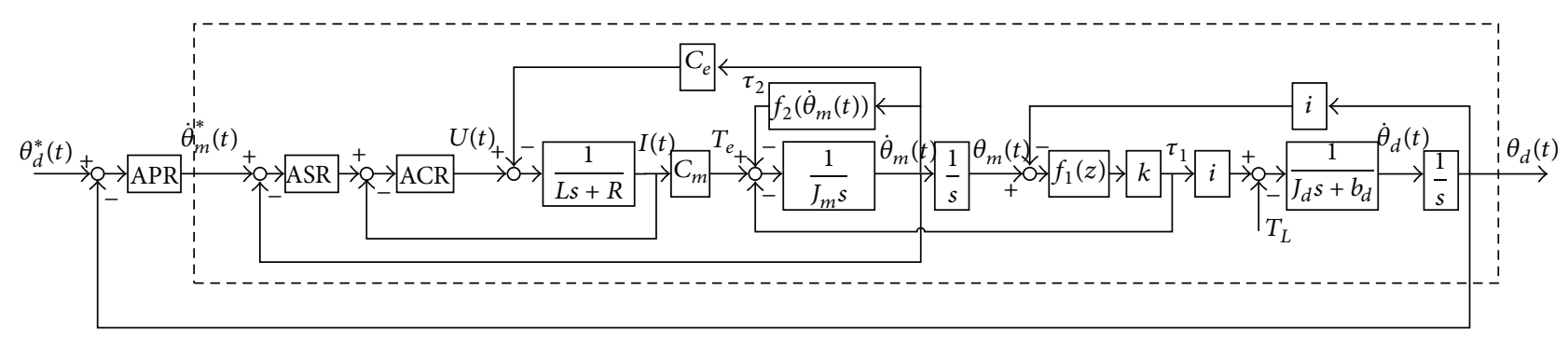

FIgURE 1: Structure diagram of the servo system.

model smooth and satisfies the above assumptions [6]. The dynamic equation of the system is expressed as

$$
\begin{gathered}
U(t)=C_{e} \dot{\theta}_{m}(t)+R I(t)+L \dot{I}(t) \\
J_{m} \ddot{\theta}_{m}(t)=T_{e}-\tau_{1}-\tau_{2} \\
J_{d} \ddot{\theta}_{d}(t)+b_{d} \dot{\theta}_{d}(t)=i \tau_{1}-T_{L} \\
T_{e}=C_{m} I(t) \\
\tau_{1}=k_{1} f_{1}(z)=k_{1}\left(z-\alpha\left(\frac{2}{1+e^{-r z}}-1\right)\right) \\
\tau_{2}=f_{2}\left(\theta_{m}\right)=\left[F_{c}+\left(F_{s}-F_{c}\right) e^{-\left(\dot{\theta}_{m} / \dot{\theta}_{s}\right)}\right] \\
\cdot \frac{2}{\pi} \arctan \left(k_{2} \theta_{m}\right)+b_{m} \dot{\theta}_{m},
\end{gathered}
$$

where $U(t), I(t), R, L, C_{e}$, and $C_{m}$ denote the armature voltage, armature current, the resistance, the inductance, the back electromotive force (EMF) coefficient, and the torque coefficient of the motor, respectively. $\theta_{m}, \dot{\theta}_{m}, \ddot{\theta}_{m}, J_{m}, b_{m}$, $\theta_{d}, \dot{\theta}_{d}, \ddot{\theta}_{d}, J_{d}$, and $b_{d}$ denote the angular displacement, the angular velocity, the angular acceleration, the rotational inertia, the viscous friction coefficient of the motor, and the load, respectively. $\tau_{1}, \tau_{2}, k_{1}, i, T_{e}$, and $T_{L}$ denote the elastic torque between the motor and the load, the friction torque, the stiffness coefficient, the gear ratio, the torque of the motor, and the load, respectively. $f_{1}$ and $f_{2}$ denote the dead-zone function and the Stribeck friction function, respectively [18, 19]. $z\left(z=\theta_{m}-i \theta_{d}\right)$ and $\alpha$ denote the relative angular displacement between the motor and the load and half of the backlash width, respectively. $F_{c}, F_{s}$, and $\dot{\theta}_{s}$ denote the Coulomb friction, the maximum static friction, and the Stribeck speed, respectively. $r$ and $k_{2}$ are undetermined parameters reflecting the approximation degree. The structure of the system is shown in Figure 1. ACR, ASR, and APR are PI current controller, PI speed controller, and the proposed position controller, respectively, and the structure in the dashed box represents the dynamic model of the servo system. $\theta_{d}^{*}(t)$ is the variable position command signal which is unknown beforehand, and the sine signal is often adopted as the testing command signal in practical servo systems.

To verify the effectiveness of the proposed characteristic model, the simulations are performed in MATLAB environment. The scheme of verifying the characteristic model

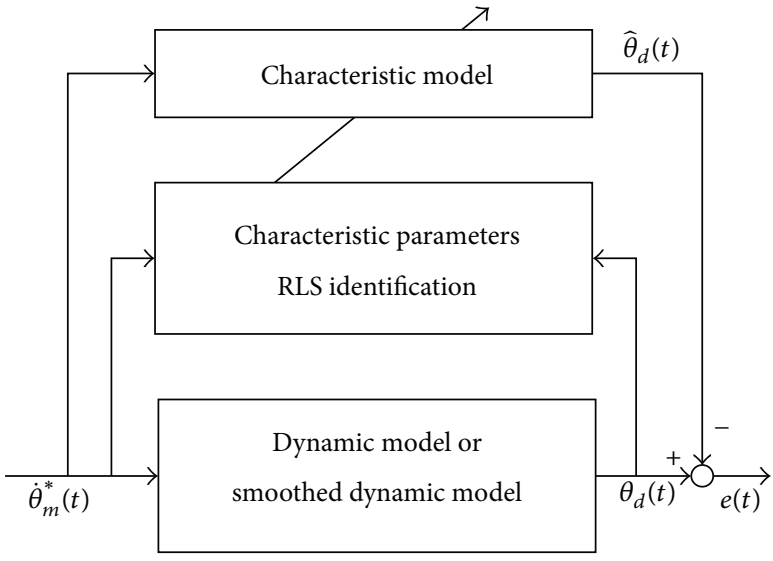

FIGURE 2: Scheme of verifying the characteristic model.

is shown in Figure 2. The output of the dynamic model is adopted as the standard output. The recursive least squares (RLS) method with forgetting factor is adopted to estimate the time-varying parameters online. $\dot{\theta}_{m}{ }^{*}(t)$ is the system input. $\theta_{d}(t)$ and $\hat{\theta}_{d}(t)$ are the dynamic model output and the characteristic model output, respectively. $e(t)$ is the error between dynamic model output and characteristic model output. $\dot{\theta}_{m}{ }^{*}(t)$ and $\theta_{d}(t)$ represent the variables $u$ and $x$, respectively, in (4).

The system parameters are $R=1.3 \Omega, L=0.0375 \mathrm{H}$, $C_{e}=67.2 \mathrm{~V} / \mathrm{krpm}, C_{m}=1.11 \mathrm{~N} \cdot \mathrm{m} / \mathrm{A}, J_{m}=0.000323 \mathrm{~kg} \cdot \mathrm{m}^{2}$, $J_{d}=54.8542 \mathrm{~kg} \cdot \mathrm{m}^{2}, k_{1}=1.3 \times 10^{6} \mathrm{~N} \cdot \mathrm{m} / \mathrm{rad}, b_{m}=0.015 \mathrm{~N} \cdot \mathrm{m} /$ $\mathrm{krpm}, b_{d}=0.024 \mathrm{~N} \cdot \mathrm{m} / \mathrm{krpm}, i=178, \alpha=0.18^{\circ}, r=2 / \alpha$, $F_{c}=0.2 \mathrm{~N} \cdot \mathrm{m}, F_{s}=0.3 \mathrm{~N} \cdot \mathrm{m}, \dot{\theta}_{s}=0.05 \mathrm{rad} / \mathrm{s}$, and $k_{2}=10$.

The results of verifying the characteristic model are shown in Figures 3, 4, and 5. $\widehat{f}_{1}(k), \widehat{f}_{2}(k)$, and $\widehat{g}_{0}(k)$ are identification values of the time-varying parameters $f_{1}(k)$, $f_{2}(k)$, and $g_{0}(k)$, respectively, in (4).

According to Figures 3, 4, and 5, the error between smoothed dynamic model and dynamic model and the error between characteristic model and the dynamic model are both very small, and the steady state error between characteristic model and dynamic model caused by the use of continuous differentiable approximate function is also very small and is considered in the following section. The results indicate that the characteristic model can properly describe the electromechanical system. 

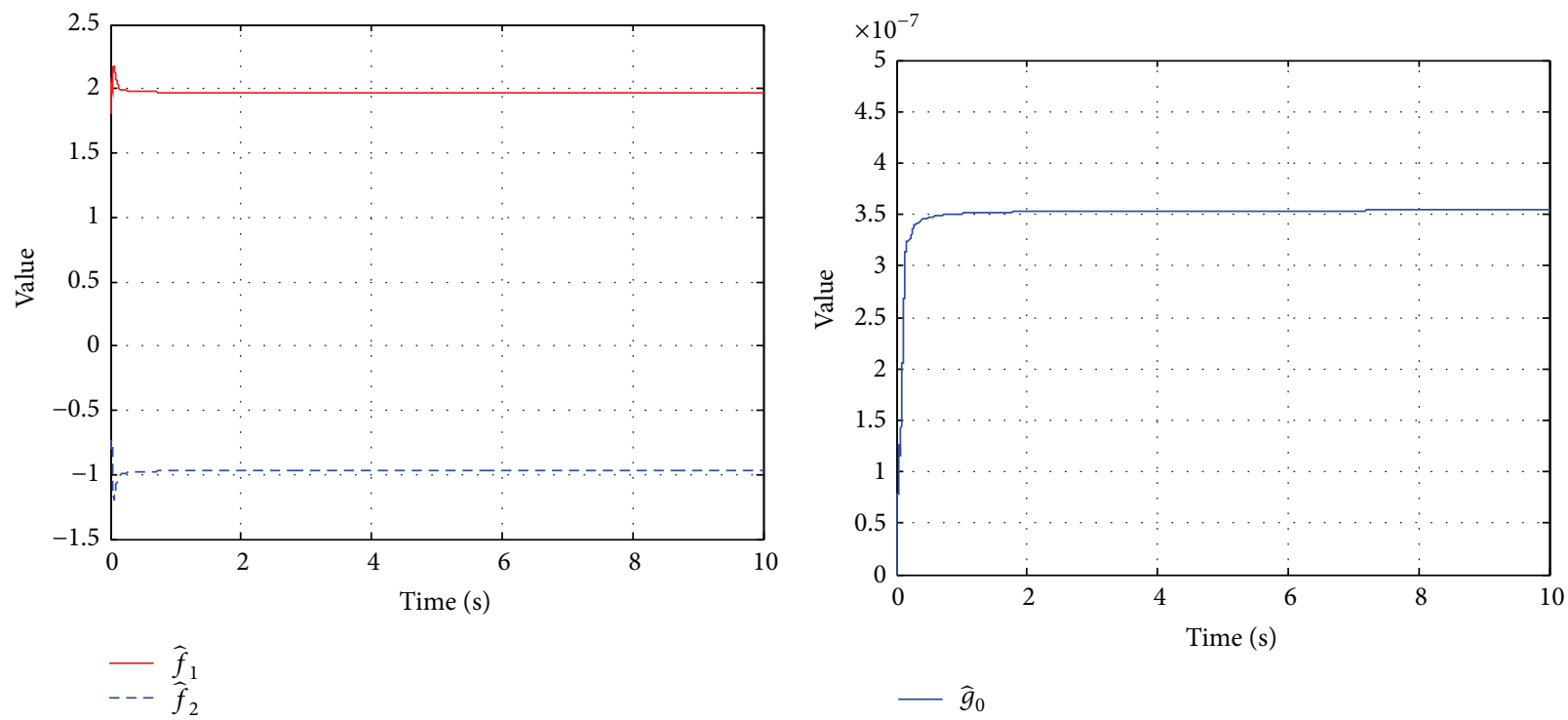

(a) $\widehat{f}_{1}(k)$ and $\widehat{f}_{2}(k)$
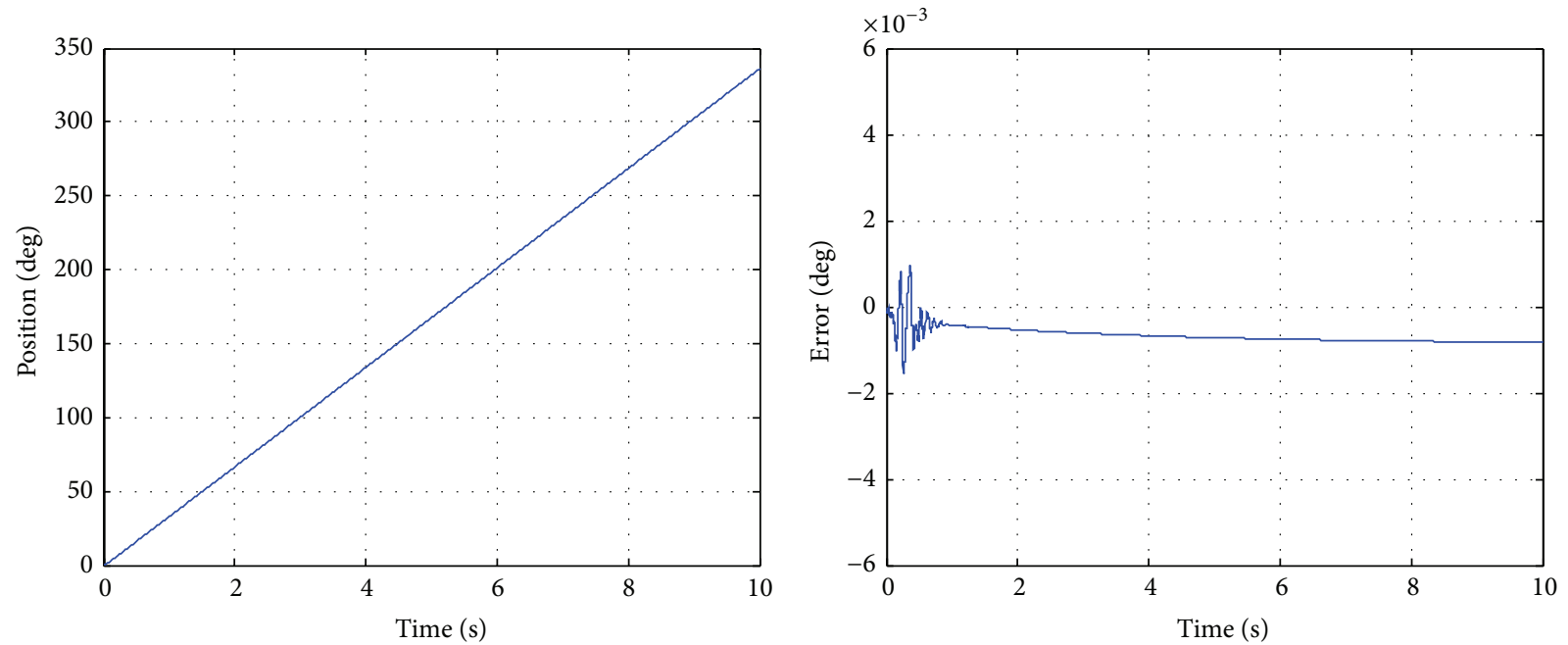

(c) Characteristic model output

(d) Error between dynamic model output and smoothed dynamic model output

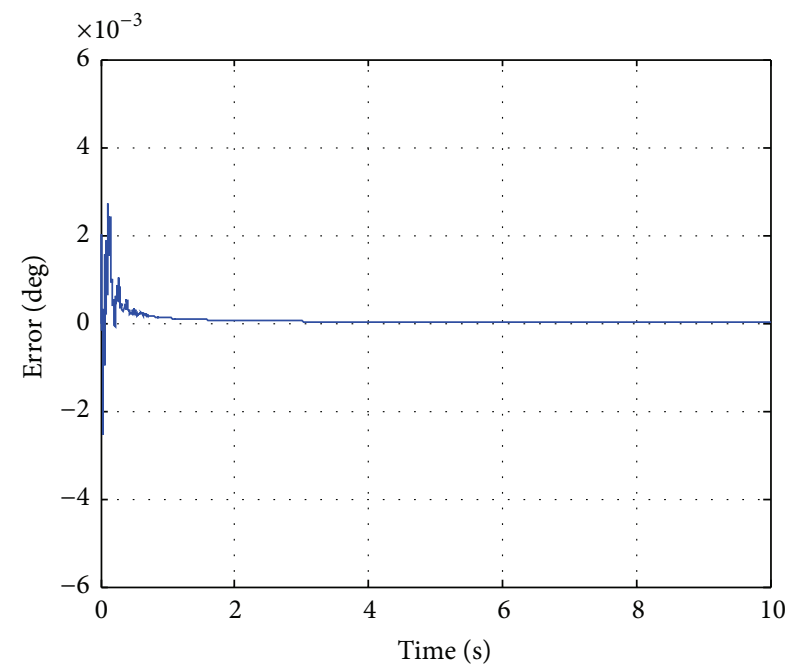

(e) Error between smoothed dynamic model output and characteristic model output

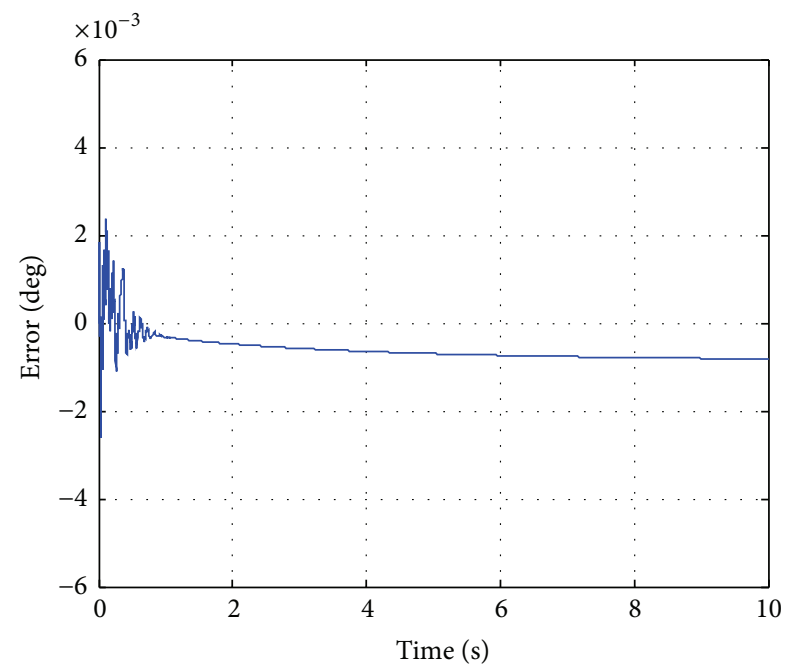

(f) Error between dynamic model output and characteristic model output

FIgURE 3: Verification results when $\dot{\theta}^{*}(t)=1000 \mathrm{rpm}$. 


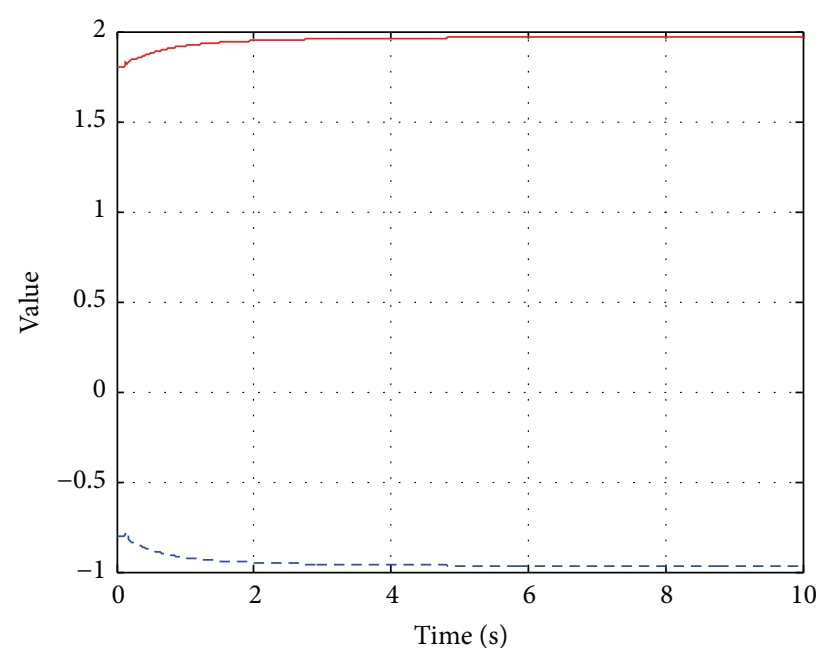

$-\widehat{f}_{1}$

(a) $\widehat{f}_{1}(k)$ and $\widehat{f}_{2}(k)$

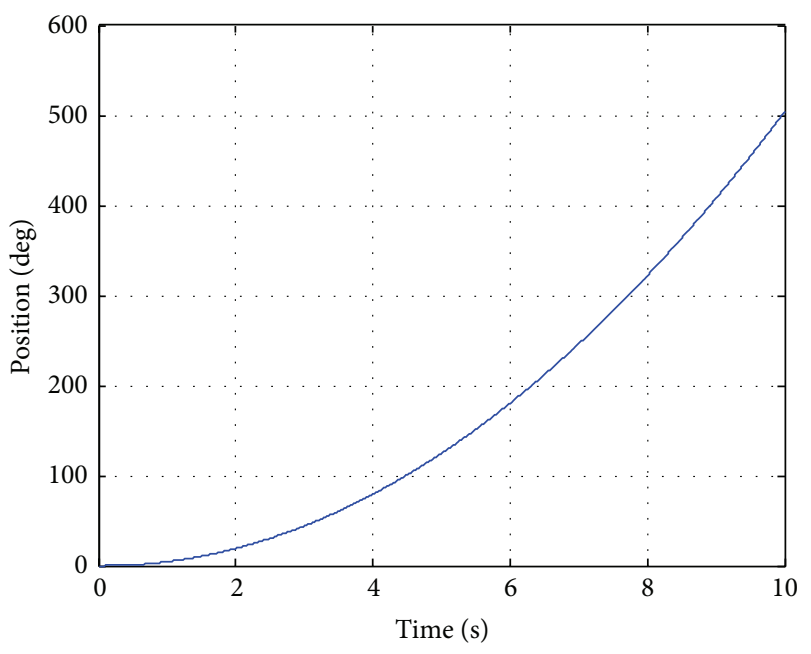

(c) Characteristic model output

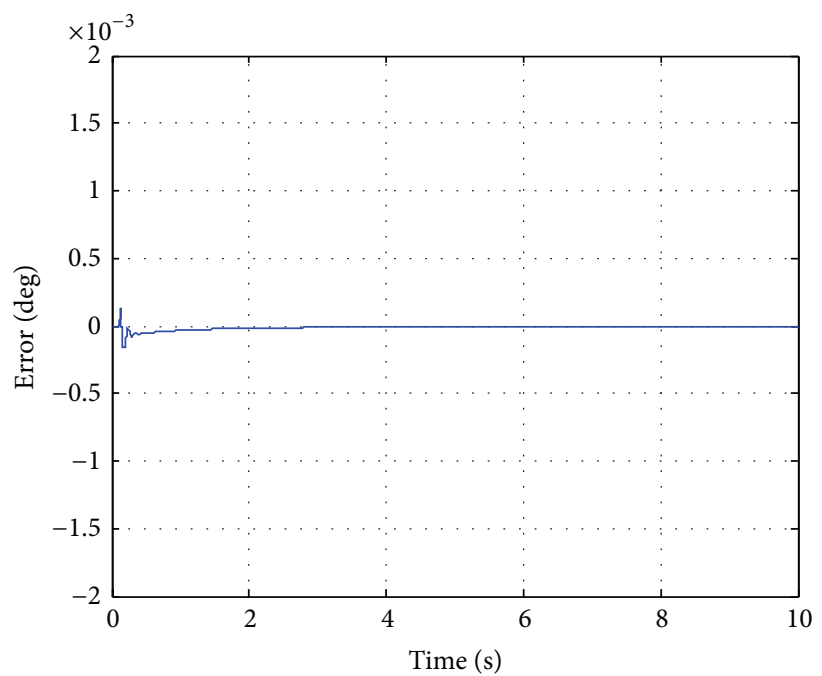

(e) Error between smoothed dynamic model output and characteristic model output

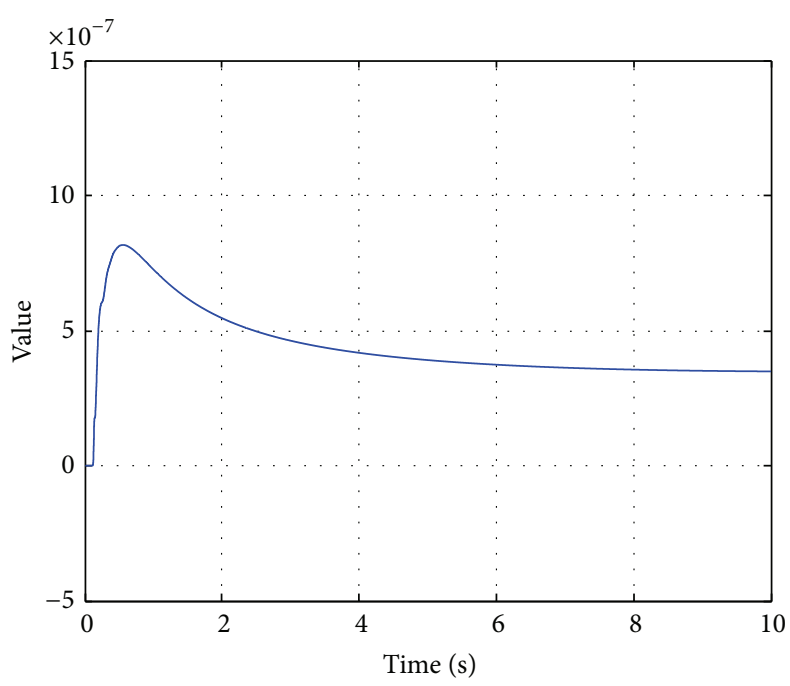

$-\widehat{g}_{0}$

(b) $\widehat{g}_{0}(k)$

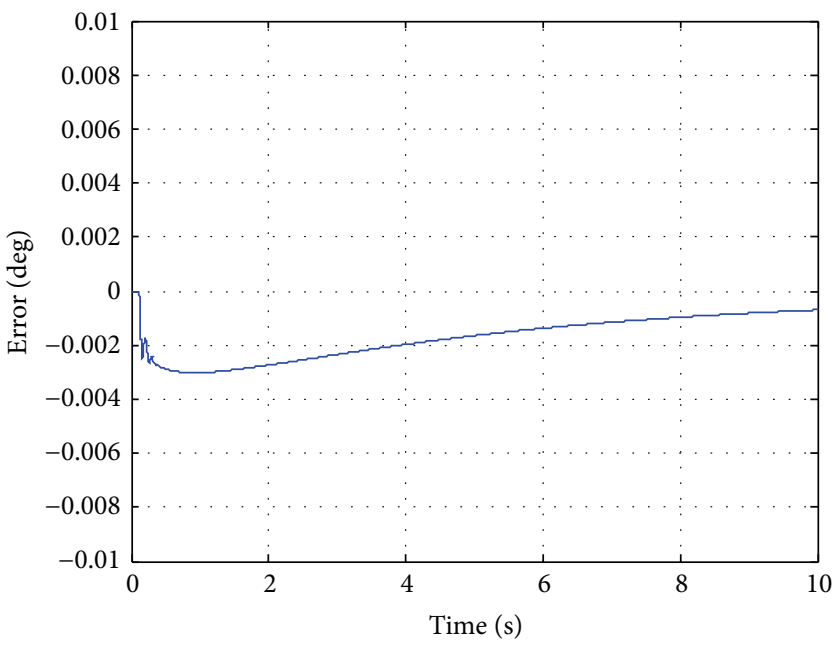

(d) Error between dynamic model output and smoothed dynamic model output

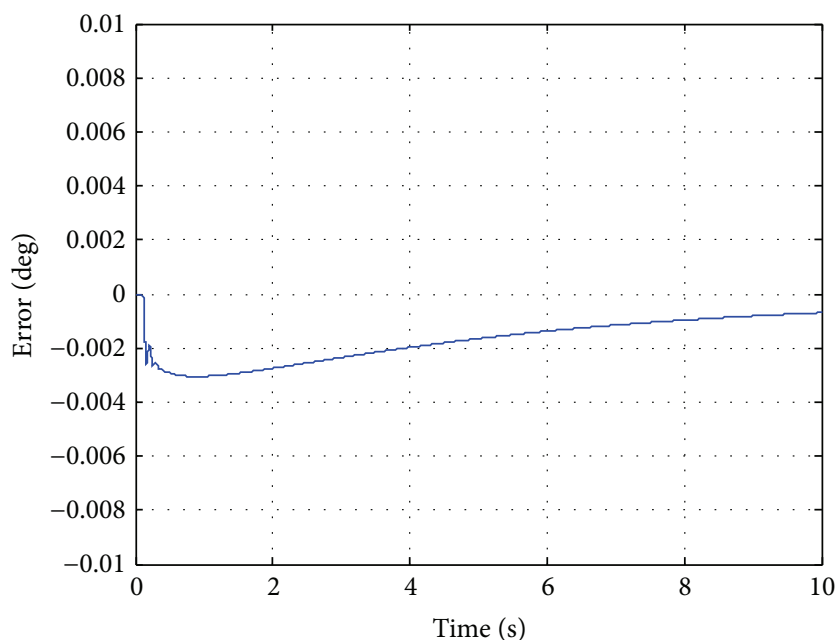

(f) Error between dynamic model output and characteristic model output

Figure 4: Verification results when $\dot{\theta}^{*}(t)=300 t \mathrm{rpm}$. 

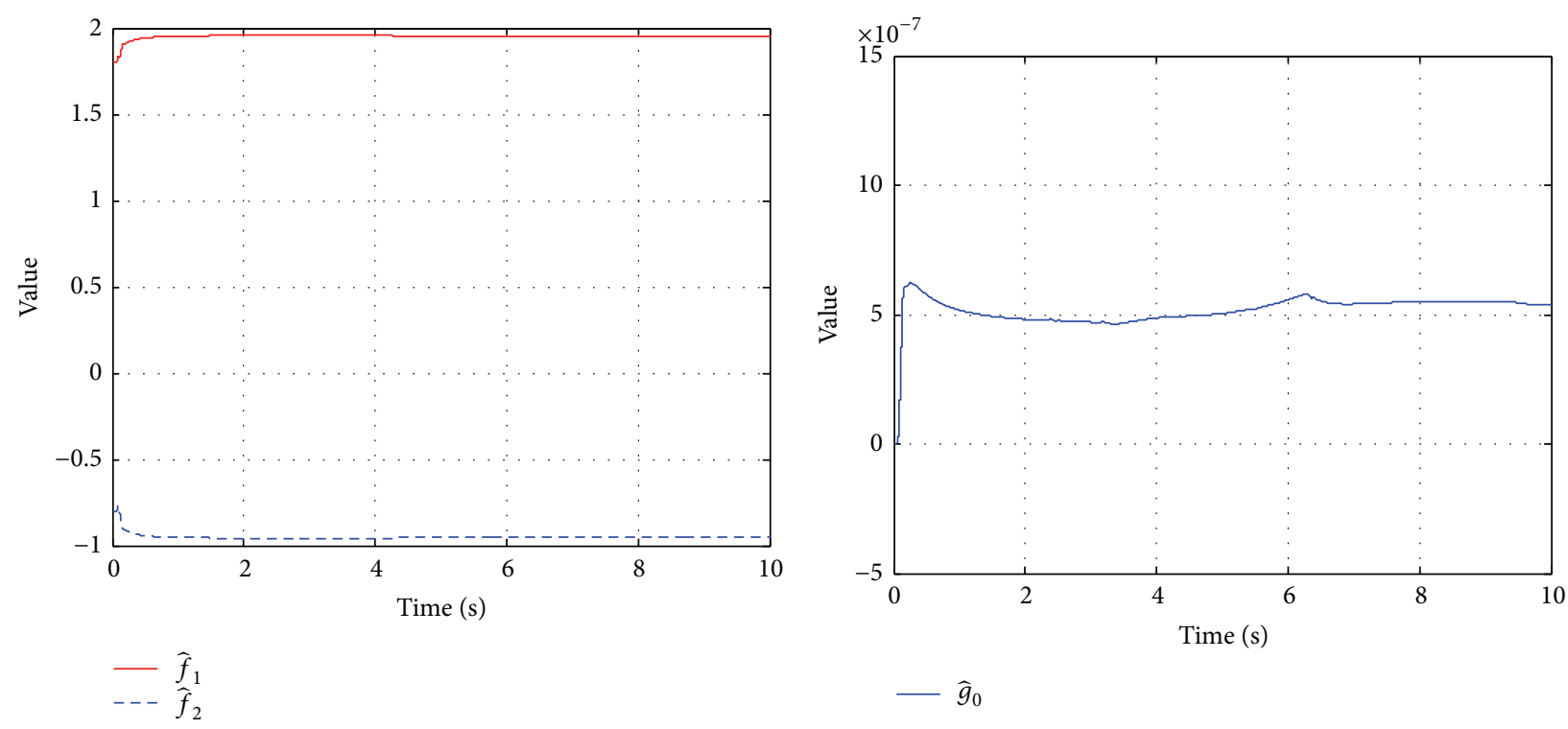

$-\widehat{g}_{0}$

(a) $\widehat{f}_{1}(k)$ and $\widehat{f}_{2}(k)$

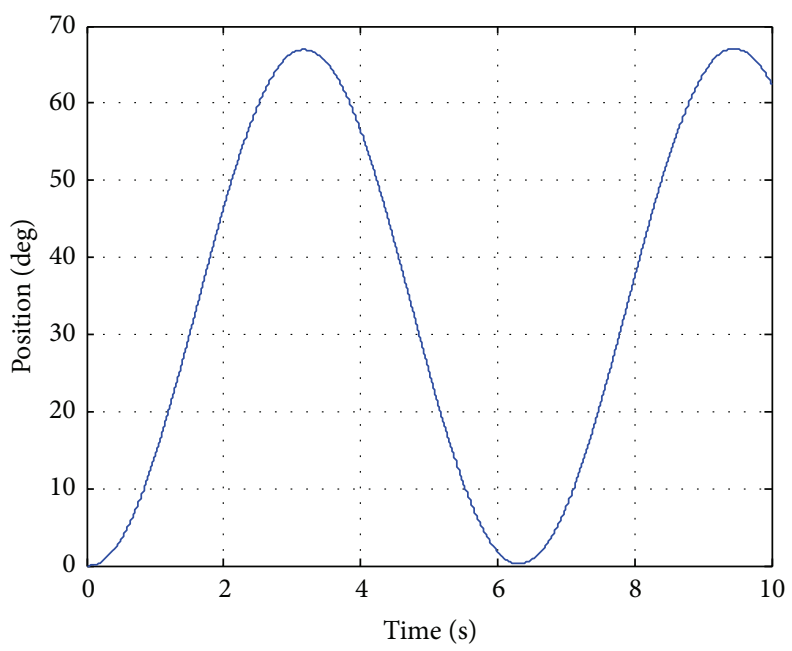

(c) Characteristic model output

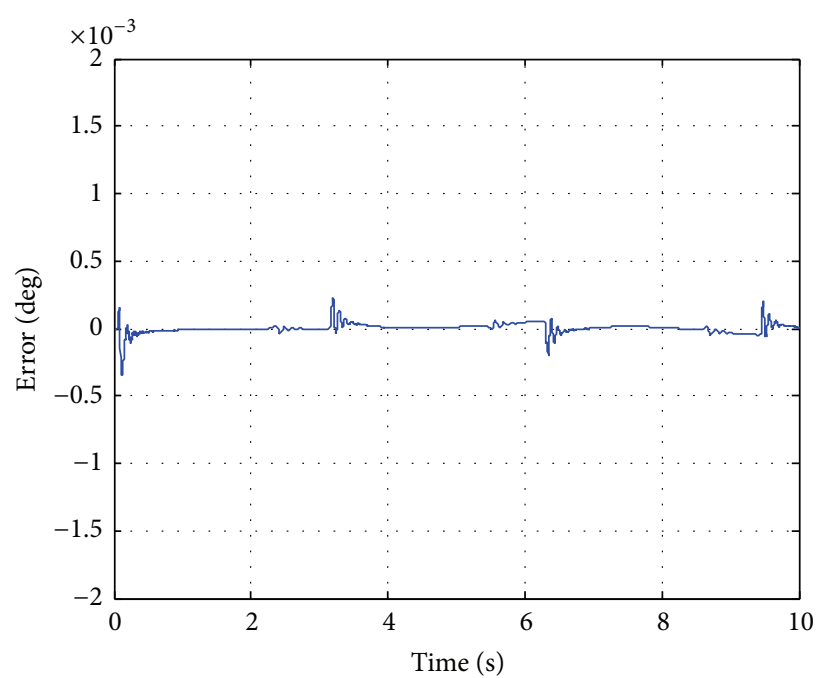

(e) Error between smoothed dynamic model output and characteristic model output

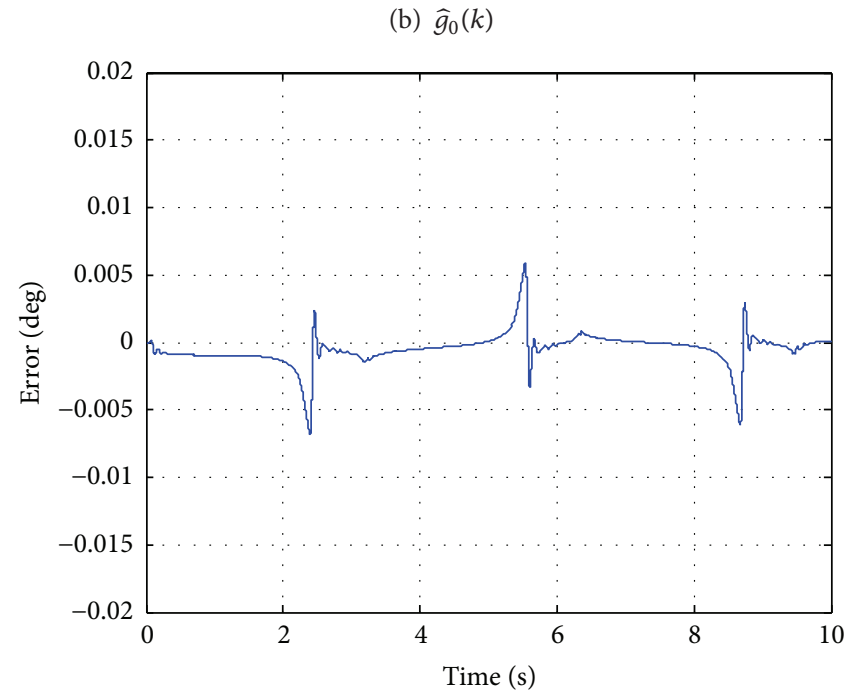

(d) Error between dynamic model output and smoothed dynamic model output

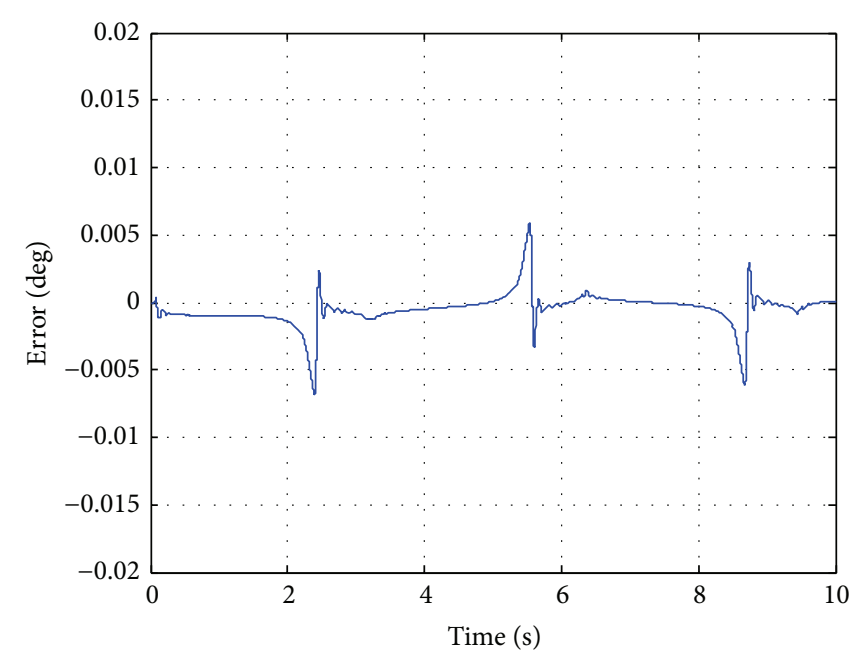

(f) Error between dynamic model output and characteristic model output 


\section{Controller Design and Stability Analysis}

The command value of next sample time $y_{d}(k+1)$ is used in the proposed DSSMAC controller later in the chapter; the following command observer is designed to obtain the value of $y_{d}(k+1)$. Assume that the command signal could be expressed with a second-order difference equation as

$$
\begin{aligned}
& x_{1}(k+1)=x_{1}(k)+T x_{2}(k) \\
& x_{2}(k+1)=x_{2}(k)+T \varphi(k),
\end{aligned}
$$

where $y_{d}(k)=x_{1}(k),|\varphi(k)|<\mu, \mu>0$, and $T$ is the sample period. Equation (6) can describe most command signals with acceleration, and $|\varphi(k)|<\mu$ indicated that the acceleration is bounded.

The command observer is designed as

$$
\begin{gathered}
\widehat{x}_{1}(k+1)=\widehat{x}_{1}(k)+T \hat{x}_{2}(k)+\alpha T \tilde{x}_{1}(k) \\
\widehat{x}_{2}(k+1)=\widehat{x}_{2}(k)+\beta T \tilde{x}_{1}(k),
\end{gathered}
$$

where $\alpha>0$ and $\beta>0$ are the parameters to be designed and $\tilde{x}_{i}(k)=x_{i}(k)-\widehat{x}_{i}(k)$ denotes the estimation error $(i=1,2)$.

Subtract (7) from (6) to obtain

$$
\begin{gathered}
\tilde{x}_{1}(k+1)=(1-\alpha T) \tilde{x}_{1}(k)+T \tilde{x}_{2}(k) \\
\tilde{x}_{2}(k+1)=-\beta T \tilde{x}_{1}(k)+\tilde{x}_{2}(k)+T \varphi(k) .
\end{gathered}
$$

Define $\widetilde{X}(k)=\left[\begin{array}{ll}\tilde{x}_{1}(k) & \tilde{x}_{2}(k)\end{array}\right]^{T}$; then, the above equation can be written as $\widetilde{X}(k+1)=A \widetilde{X}(k)+B \varphi(k)$, where

$$
A=\left[\begin{array}{cc}
1-\alpha T & T \\
-\beta T & 1
\end{array}\right], \quad B=\left[\begin{array}{l}
0 \\
T
\end{array}\right]
$$

Define $a=\alpha T-1$ and $b=\beta T$; then,

$$
A=\left[\begin{array}{ll}
-a & T \\
-b & 1
\end{array}\right], \quad B=\left[\begin{array}{l}
0 \\
T
\end{array}\right] .
$$

Consider a matrix $P$ as

$$
P=\left[\begin{array}{ll}
p_{1} & p_{2} \\
p_{2} & p_{3}
\end{array}\right]
$$

where

$$
\begin{gathered}
p_{1}=\frac{a b-2 T-b-b^{2} T}{T(a-b T+1)(2 a-b T-2)} \\
p_{2}=\frac{-a^{2}+a b T+T^{2}+1}{T(a-b T+1)(2 a-b T-2)} \\
p_{3}=\frac{a^{3}-a^{2} b T+a^{2}+a T^{2}-a-b T^{3}-T^{2}-b T-1}{b T(a-b T+1)(2 a-b T-2)} .
\end{gathered}
$$

Then, through a fundamental algebra operation, we get $A^{T} P A-P=-I$, where $I$ is a unit matrix.

The parameters $\alpha$ and $\beta$ are chosen to satisfy the following condition, which gives $P=P^{T}>0$ :

$$
\begin{gathered}
F_{2}(a, b, T)>0 \\
\frac{\left[F_{1}(a, b, T)+\sqrt{F_{2}(a, b, T)}\right]}{F_{3}(a, b, T)}>0 \\
\frac{\left[F_{1}(a, b, T)-\sqrt{F_{2}(a, b, T)}\right]}{F_{3}(a, b, T)}>0,
\end{gathered}
$$

where

$$
\begin{aligned}
F_{1}(a, b, T)= & a b^{2}+a T^{2}-b T^{3}-b^{3} T-a \\
& -3 b T+a^{3}+a^{2}-b^{2}-T^{2}-a^{2} b T-1 \\
F_{2}(a, b, T)= & a^{6}-2 a^{5} b T+2 a^{5}+a^{4} b^{2} T^{2}+2 a^{4} b^{2} \\
& -2 a^{4} b T+2 a^{4} T^{2}-a^{4}-4 a^{3} b^{3} T-4 a^{3} b T^{3} \\
+ & 4 a^{3} b T-4 a^{3}+2 a^{2} b^{4} T^{2}+a^{2} b^{4}+2 a^{2} b^{2} T^{4} \\
& -12 a^{2} b^{2} T^{2}-4 a^{2} b^{2}+4 a^{2} b T+a^{2} T^{4} \\
& -4 a^{2} T^{2}-a^{2}-2 a b^{5} T-2 a b^{4}+12 a b^{3} T^{3} \\
+ & 4 a b^{3} T+4 a b^{2} T^{2}-2 a b T^{5}+4 a b T^{3} \\
- & 2 a b T-2 a T^{4}+2 a+b^{6} T^{2}+2 b^{5} T-2 b^{4} T^{4} \\
+ & 2 b^{4} T^{2}+b^{4}-4 b^{3} T^{3}+b^{2} T^{6} \\
+ & 2 b^{2} T^{4}+7 b^{2} T^{2}+2 b^{2}+2 b T^{5} \\
- & 2 b T+T^{4}+2 T^{2}+1 \\
F_{3}(a, b, & T)=2 b T(a-b T+1)(2 a-b T-2) .
\end{aligned}
$$

Theorem 2. If observer (7) is applied to system (6) and $\alpha$ and $\beta$ are chosen to satisfy condition (13), then the observation error is bounded stable.

Proof. Take $V[\widetilde{X}(k)]=\widetilde{X}(k)^{T} P \widetilde{X}(k)$ as the Lyapunov equation; then,

$$
\begin{aligned}
\Delta V[\widetilde{X}(k)]= & V[\widetilde{X}(k+1)]-V[\widetilde{X}(k)] \\
= & \widetilde{X}(k+1)^{T} P \widetilde{X}(k+1)-\widetilde{X}(k)^{T} P \widetilde{X}(k) \\
= & \widetilde{X}(k)^{T}\left(A^{T} P A-P\right) \widetilde{X}(k) \\
& +2 B^{T} P A \widetilde{X}(k) \varphi(k)+B^{T} P B \varphi^{2}(k)
\end{aligned}
$$




$$
\begin{aligned}
& =-\|\widetilde{X}(k)\|^{2}+2 B^{T} P A \widetilde{X}(k) \varphi(k)+B^{T} P B \varphi^{2}(k) \\
& <-\|\widetilde{X}(k)\|^{2}+2 \mu\left\|B^{T} P A\right\|\|\widetilde{X}(k)\|+\mu^{2}\left\|B^{T} P B\right\| .
\end{aligned}
$$

Obviously, $\Delta V[\widetilde{X}(k)]<0$ when $\|\widetilde{X}(k)\|>\mu\left(\left\|B^{T} P A\right\|+\right.$ $\left.\sqrt{\left\|B^{T} P A\right\|^{2}+\left\|B^{T} P B\right\|}\right)$; then, the set $\Omega=\{\widetilde{X}(k) \mid\|\widetilde{X}(k)\| \leq$ $\left.\mu\left(\left\|B^{T} P A\right\|+\sqrt{\left\|B^{T} P A\right\|^{2}+\left\|B^{T} P B\right\|}\right)\right\}$ is an invariant set. If $\widetilde{X}(k)$ is outside the set $\Omega$, then it will finally come back inside set $\Omega$; that is, $\|\widetilde{X}(k)\|$ is bounded stable. follows:

The characteristic model of the system can be written as

$$
\begin{aligned}
y(k+1)= & \widehat{f}_{1}(k) y(k)+\widehat{f}_{2}(k) y(k-1) \\
& +\widehat{g}_{0}(k) u(k)+\Delta_{1}(k),
\end{aligned}
$$

where $\widehat{f}_{1}(k), \widehat{f}_{2}(k)$, and $\widehat{g}_{0}(k)$ are the estimation of $f_{1}(k)$, $f_{2}(k)$, and $g_{0}(k)$ and $\Delta_{1}(k)$ denotes the model identification error. $y(k)$ represents $\theta_{d}(k)$, which denotes the output of the model, and $u(k)$ represents $\dot{\theta}_{m}{ }^{*}(k)$, which denotes the output of the designed controller or the control input of the plant; define $e(k)=y_{d}(k)-y(k)$ as the tracking error; then,

$$
\begin{aligned}
e(k+1) & =y_{d}(k+1)-y(k+1) \\
& =\widehat{y}_{d}(k+1)-\Delta_{2}(k)-y(k+1),
\end{aligned}
$$

where $y_{d}(k+1)$ denotes the variable unknown position command value of next sample time, $\widehat{y}_{d}(k+1)$ is the estimation value of $y_{d}(k+1)$, and $\Delta_{2}(k)$ denotes the command estimation error.

Define $\Delta(k)=\Delta_{1}(k)+\Delta_{2}(k)$. Assuming $|\Delta(k)-\Delta(k-1)|<$ $\delta$, where $\delta>0$ is a positive constant, then substituting (16) into (17), we obtain

$$
\begin{aligned}
e(k+1)= & \widehat{y}_{d}(k+1)-\widehat{f}_{1}(k) y(k) \\
& -\widehat{f}_{2}(k) y(k-1)-\widehat{g}_{0}(k) u(k)-\Delta(k) .
\end{aligned}
$$

The sliding function is defined as $s(k)=c e(k)$, and the second-order sliding function is defined as $\sigma(k+1)=s(k+$ $1)+\beta s(k)$, where the parameters $c>0$ and $0<\beta<1$ are the parameters to be designed. When reaching the sliding mode surface, we obtain $\sigma(k+1)=\sigma(k)=0$; that is, $e(k+1)=$ $-\beta e(k)$; then, (18) becomes

$$
\begin{aligned}
\beta e(k) & +\widehat{y}_{d}(k+1)-\widehat{f}_{1}(k) y(k) \\
& -\widehat{f}_{2}(k) y(k-1)-\widehat{g}_{0}(k) u(k)-\Delta(k)=0 .
\end{aligned}
$$

The equivalent control is obtained from (19) as

$$
\begin{aligned}
u_{\mathrm{eq}}(k)= & \frac{1}{\widehat{g}_{0}(k)} \\
& \cdot\left[\beta e(k)+\widehat{y}_{d}(k+1)\right. \\
& \left.\quad-\widehat{f}_{1}(k) y(k)-\widehat{f}_{2}(k) y(k-1)\right],
\end{aligned}
$$

where $\widehat{y}_{d}(k+1)$ is the command estimation value, which can be obtained from (7).

The switching control $u_{s}(k)$ is designed as

$$
u_{s}(k)=\frac{1}{\widehat{g}_{0}(k)}\left\{\widehat{g}_{0}(k-1) u_{s}(k-1)+M \operatorname{sgn}[\sigma(k)]\right\},
$$

where $M>\delta$ is the parameter to be designed; then, combining (20) and (21), the total control action is designed as

$$
u(k)=u_{\mathrm{eq}}(k)+u_{s}(k) .
$$

Theorem 3. If controller (22) is applied to system (16) and $c>$ $0,0<\beta<1, M>\delta$, then the closed-loop system is stable.

Proof. Take (22) into (18) to obtain

$$
\begin{aligned}
e(k+1) & \\
= & -\beta e(k)-\widehat{g}_{0}(k) u_{s}(k)-\Delta(k) \\
= & -\beta e(k)-\widehat{g}_{0}(k-1) u_{s}(k-1) \\
& -M \operatorname{sgn}[\sigma(k)]-\Delta(k) .
\end{aligned}
$$

Equation (23) can be rewritten as

$$
e(k)=-\beta e(k-1)-\widehat{g}_{0}(k-1) u_{s}(k-1)-\Delta(k-1) .
$$

Subtract (24) from (23) to obtain

$$
\begin{aligned}
e(k+1)-e(k)= & -\beta[e(k)-e(k-1)] \\
& -M \operatorname{sgn}[\sigma(k)]-[\Delta(k)-\Delta(k-1)] .
\end{aligned}
$$

that is,

$$
\sigma(k+1)-\sigma(k)=-c\{M \operatorname{sgn}[\sigma(k)]+[\Delta(k)-\Delta(k-1)]\}
$$

such that

$$
\begin{aligned}
& {[\sigma(k+1)-\sigma(k)] \operatorname{sgn}[\sigma(k)]} \\
& \quad=-c\{M+[\Delta(k)-\Delta(k-1)] \operatorname{sgn}[\sigma(k)]\} \\
& \quad<-c(M-\delta)<0 .
\end{aligned}
$$

Define the quasi-sliding mode band width $\varepsilon=c(M+\delta)$; according to (24) when $|\sigma(k)|>\varepsilon$, we have

$$
\begin{aligned}
\sigma(k) \operatorname{sgn}[\sigma(k)]= & -c\left[\hat{g}(k-1) u_{s}(k-1)+\Delta(k-1)\right] \\
& \cdot \operatorname{sgn}[\sigma(k)]>c(M+\delta) ;
\end{aligned}
$$

that is,

$$
\begin{aligned}
& -\widehat{g}(k-1) u_{s}(k-1) \operatorname{sgn}[\sigma(k)] \\
& \quad>M+\delta+\Delta(k-1) \operatorname{sgn}[\sigma(k)] .
\end{aligned}
$$


According to (23), (24), and (29), we obtain

$$
\begin{aligned}
& {[\sigma(k+1)+\sigma(k)] \operatorname{sgn}[\sigma(k)]} \\
& =c\left\{-2 \widehat{g}(k-1) u_{s}(k-1)\right. \\
& -M \operatorname{sgn}[\sigma(k)]-\Delta(k)-\Delta(k-1)\} \operatorname{sgn}[\sigma(k)] \\
& =c\left\{-2 \widehat{g}(k-1) u_{s}(k-1) \operatorname{sgn}[\sigma(k)]\right. \\
& -M-[\Delta(k)+\Delta(k-1)] \operatorname{sgn}[\sigma(k)]\} \\
& >c\{2(M+\delta)+2 \Delta(k-1) \operatorname{sgn}[\sigma(k)] \\
& -M-[\Delta(k)+\Delta(k-1)] \operatorname{sgn}[\sigma(k)]\} \\
& =c\{M+2 \delta-[\Delta(k)-\Delta(k-1)] \operatorname{sgn}[\sigma(k)]\} \\
& >c(M+\delta)>0 \text {. }
\end{aligned}
$$

When $0<|\sigma(k)|<\varepsilon$, (29) becomes

$$
\begin{aligned}
\Delta(k-1) \operatorname{sgn}[\sigma(k)] & <-\widehat{g}(k-1) u_{s}(k-1) \operatorname{sgn}[\sigma(k)] \\
& <M+\delta+\Delta(k-1) \operatorname{sgn}[\sigma(k)] .
\end{aligned}
$$

If $\operatorname{sgn}[\sigma(k+1)]=\operatorname{sgn}[\sigma(k)],(27)$ becomes $|\sigma(k+1)|<|\sigma(k)|<$ $\varepsilon$.

If $\operatorname{sgn}[\sigma(k+1)]=-\operatorname{sgn}[\sigma(k)]$, according to (23) and (31), we have

$$
\begin{aligned}
&|\sigma(k+1)|=-\sigma(k+1) \operatorname{sgn}[\sigma(k)] \\
&= c\left\{\hat{g}(k-1) u_{s}(k-1) \operatorname{sgn}[\sigma(k)]\right. \\
&+M+\Delta(k) \operatorname{sgn}[\sigma(k)]\} \\
&< c\{-\Delta(k-1) \operatorname{sgn}[\sigma(k)] \\
& \quad+M+\Delta(k) \operatorname{sgn}[\sigma(k)]\} \\
&= c\{M+[\Delta(k)-\Delta(k-1)] \operatorname{sgn}[\sigma(k)]\} \\
&<c(M+\delta)=\varepsilon .
\end{aligned}
$$

The verification of the three conditions (27), (30), and (32) proves the existence of the convergent quasisliding mode, and the quasisliding mode is reached within a finite number of steps. Therefore, the closed-loop system is stable.

\section{System Experiment}

In this section, the position loop tracking experiments are carried out on the experimental system to verify the effectiveness of the proposed controller compared with typical SMC controller. The PMSM (model: B-402-B) produced by Kollmorgen Company and the reducer (model: FIC-A3589) produced by Sumitomo Heavy Machinery Company are utilized in the experiment. The parameters of the motor and the reducer are listed in Tables 1 and 2.

The experimental system is shown in Figures 6 and 7. According to Tables 1 and 2, the inertia of the reducer is

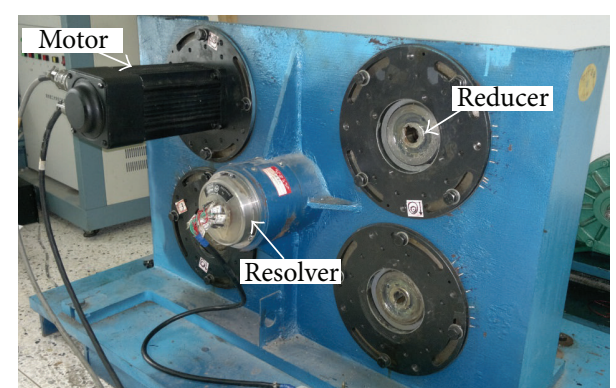

FIGURE 6: The motor side of experimental system.

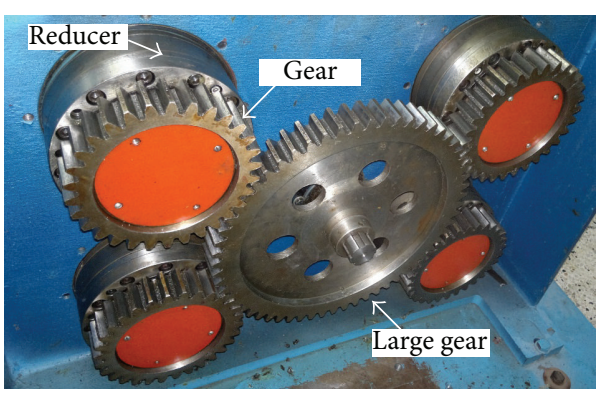

Figure 7: The load side of experimental system.

TABLE 1: Parameters of the motor (B-402-B).

\begin{tabular}{lcc}
\hline Name & Units & Value \\
\hline Rated power & $\mathrm{kW}$ & 2.2 \\
Rated speed & $\mathrm{RPM}$ & 3000 \\
Rated torque & $\mathrm{N} \cdot \mathrm{m}$ & 7.4 \\
Inertia & $\mathrm{Kg} \cdot \mathrm{m}^{2}$ & 0.000323 \\
Static friction & $\mathrm{N} \cdot \mathrm{m}$ & 0.24 \\
Viscous friction & $\mathrm{N} \cdot \mathrm{m} / \mathrm{kRPM}$ & 0.015 \\
\hline
\end{tabular}

TABle 2: Parameters of the reducer (F1C-A35-89).

\begin{tabular}{lcc}
\hline Name & Units & Value \\
\hline Reduction ratio & & 89 \\
Rated output torque & $\mathrm{N} \cdot \mathrm{m}$ & 754 \\
Input shaft inertia & $\mathrm{Kg} \cdot \mathrm{m}^{2}$ & 0.000433 \\
Max input speed & $\mathrm{RPM}$ & 3950 \\
\hline
\end{tabular}

1.34 times that of the motor. By the test, when the input speed is $2000 \mathrm{rpm}$, the friction torque of a single reducer is about $2 \mathrm{~N} \cdot \mathrm{m}$. Considering that the reduction ratio of the reducer is $1: 89$, the inertia and friction moment of the large gear converted to motor side is relatively small; therefore, it can be ignored. In the experiment, reducers are used as loads of the motor and the large gear is used for gear meshing on the output side of the reducer. In the following experiments, single motor drives different numbers of reducers by mounting and dismounting output gear of reducers to simulate different load inertia and torque, as shown in Table 3. 


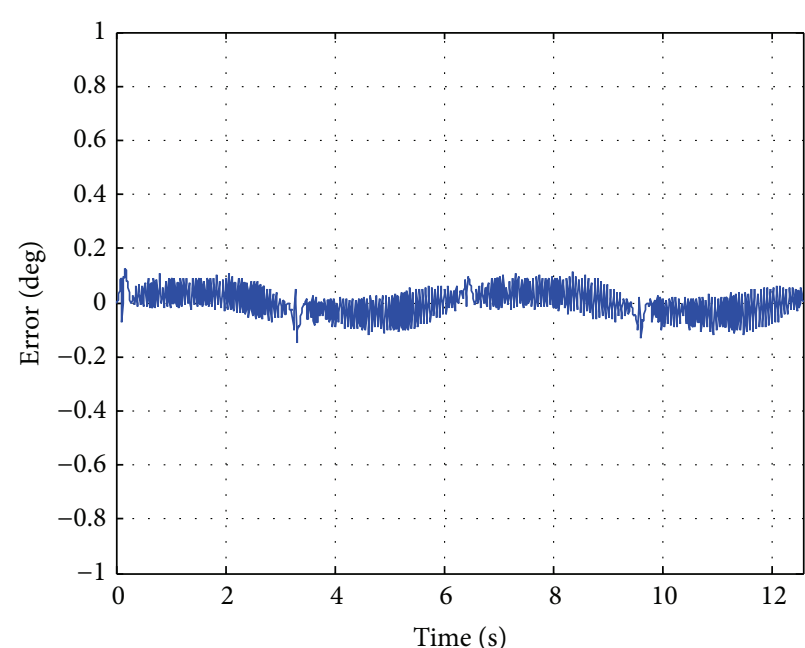

(a) $30^{\circ} / \mathrm{s}, 30^{\circ} / \mathrm{s}^{2}$ sine tracking error (SMC)

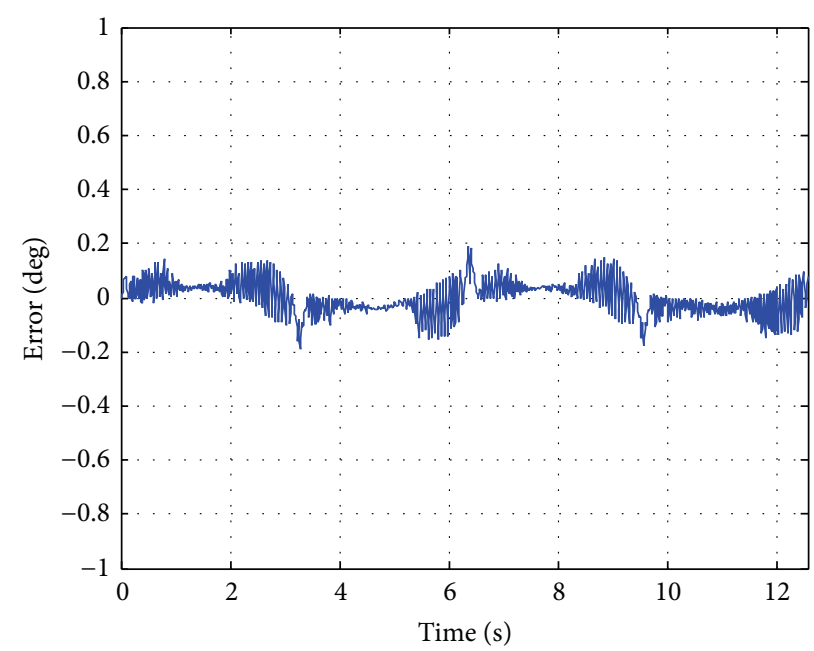

(c) $60^{\circ} / \mathrm{s}, 60^{\circ} / \mathrm{s}^{2}$ sine tracking error (SMC)

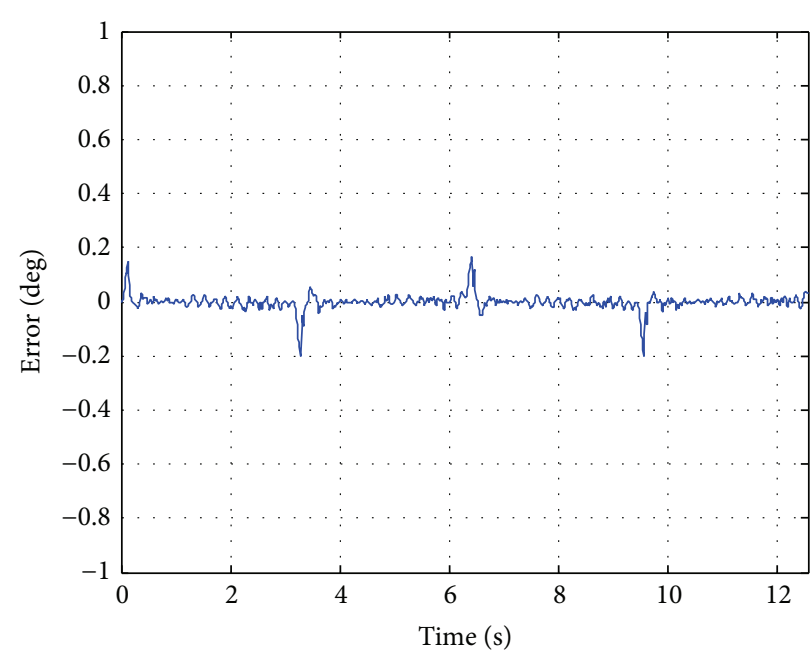

(b) $30^{\circ} / \mathrm{s}, 30^{\circ} / \mathrm{s}^{2}$ sine tracking error (DSSMAC)

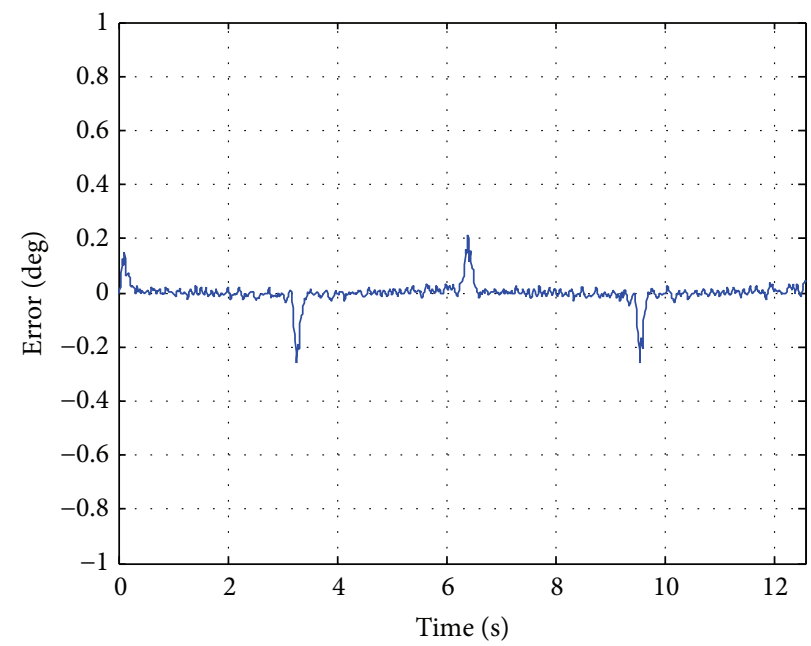

(d) $60^{\circ} / \mathrm{s}, 60^{\circ} / \mathrm{s}^{2}$ sine tracking error (DSSMAC)

FIGURE 8: Experimental results in case 1.

TABLE 3: Two experimental conditions.

\begin{tabular}{lccc}
\hline Name & $\begin{array}{c}\text { System } \\
\text { constitution }\end{array}$ & Inertia ratio & Load torque \\
\hline Case 1 & $\begin{array}{c}\text { Single motor } \\
\text { drives two } \\
\text { reducers }\end{array}$ & $2.68: 1$ & $4 \mathrm{~N} \cdot \mathrm{m}$ \\
\hline Case 2 & $\begin{array}{c}\text { Single motor } \\
\text { drives four } \\
\text { reducers }\end{array}$ & $5.36: 1$ & $8 \mathrm{~N} \cdot \mathrm{m}$ \\
\hline
\end{tabular}

After experimental adjustment, the parameters of command observer are selected as $\alpha=600, \beta=90000$, and $T=$ 0.005 , the RLS forgetting factor is $f=0.995$, the parameters of DSSMAC are $c=1.0, \beta=0.2$, and $M=0.5$, the parameters of typical SMC controller are $q=10$ and $\varepsilon=80$, where $q$ and $\varepsilon$ denote the exponential reaching speed and the constant reaching speed of the exponential reaching law, respectively, and the feedforward coefficient is $K_{w}=100.0$. Considering the max speed and max acceleration of the servo system, the $30 \%, 30^{\circ} / \mathrm{s}^{2}$ and $60 \% \mathrm{~s}, 60^{\circ} / \mathrm{s}^{2}$ sine signal was selected as the testing input signal, and the frequency of the input signal is $1 \mathrm{rad} / \mathrm{s}$. The responses of the testing sine command under different load inertia and torque are tested, respectively. The experimental results in different cases are shown in Figures 8 and 9. The tracking errors of the two methods are shown in Table 4.

As shown in Figures 8 and 9 and Table 4, periodical jumps of tracking error are caused by backlash of the system. The comparison results indicate that the tracking errors of the proposed controller are much smaller than those of SMC controller, and the chattering is also eliminated compared with the typical SMC controller. It is also noticed that in some cases the periodical error jumps of the proposed controller are larger than those of the typical sliding mode controller such as in Figures 8(a) and 8(b); that is because the peak error jumps are caused by backlash which can lead to a speed jump when the gears go across the backlash, and the chattering of the typical sliding mode controller makes the 


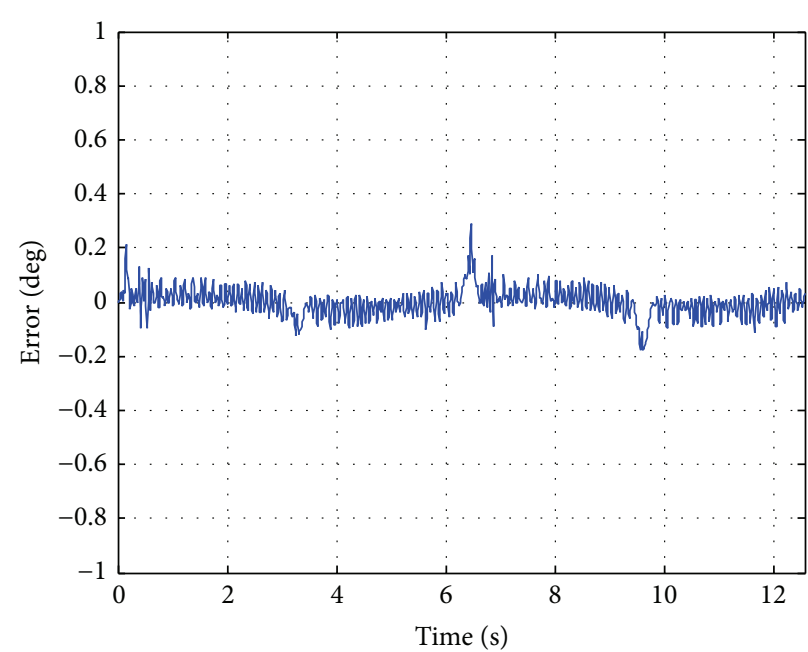

(a) $30^{\circ} / \mathrm{s}, 30^{\circ} / \mathrm{s}^{2}$ sine tracking error (SMC)

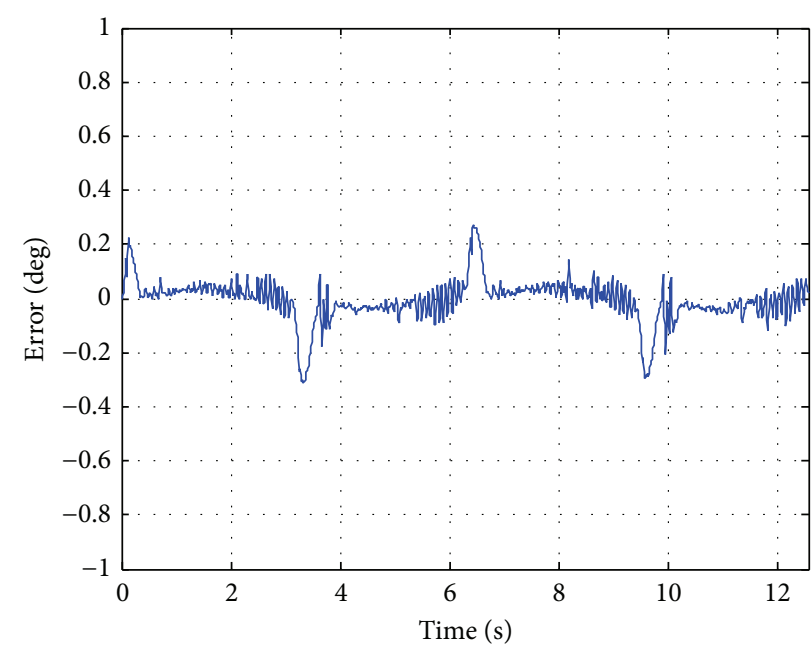

(c) $60^{\circ} / \mathrm{s}, 60^{\circ} / \mathrm{s}^{2}$ sine tracking error (SMC)

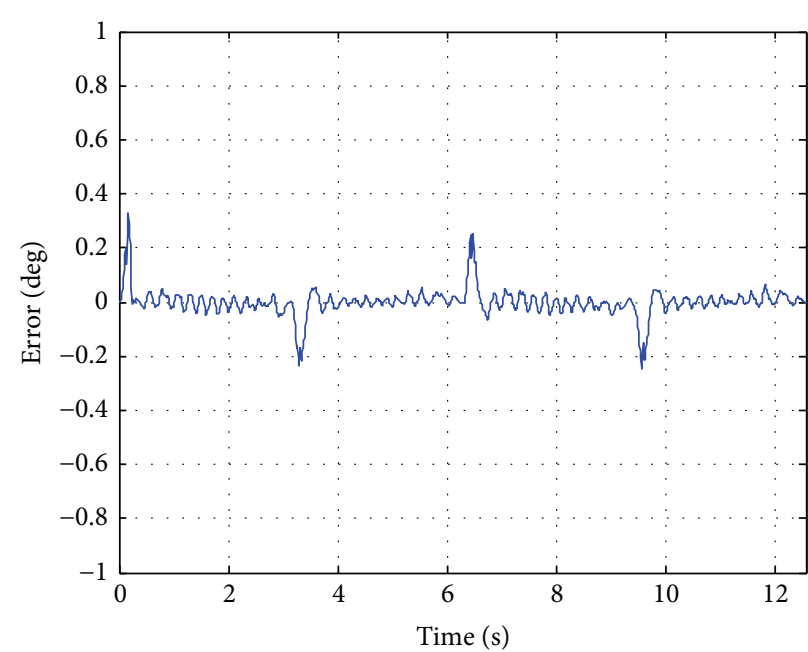

(b) $30^{\circ} / \mathrm{s}, 30^{\circ} / \mathrm{s}^{2}$ sine tracking error (DSSMAC)

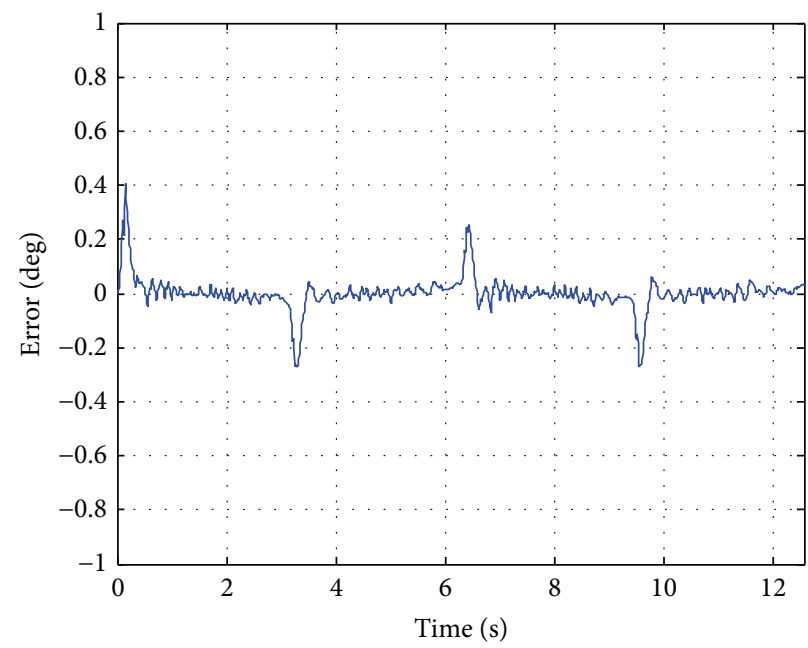

(d) $60^{\circ} / \mathrm{s}, 60^{\circ} / \mathrm{s}^{2}$ sine tracking error (DSSMAC)

FIGURE 9: Experimental results in case 2.

TABLE 4: Tracking errors in two cases.

\begin{tabular}{llcc}
\hline Case & Tracking signal & $\begin{array}{c}\text { RMS error } \\
(\text { SMC) }\end{array}$ & $\begin{array}{c}\text { RMS error } \\
(\text { DSSMAC) }\end{array}$ \\
\hline 1 & $30^{\circ} / \mathrm{s}, 30^{\circ} / \mathrm{s}^{2}$ sine & 0.052 & 0.028 \\
\hline 2 & $60^{\circ} / \mathrm{s}, 60^{\circ} / \mathrm{s}^{2}$ sine & 0.060 & 0.036 \\
\hline & $30^{\circ} / \mathrm{s}, 30^{\circ} / \mathrm{s}^{2}$ sine & 0.051 & 0.049 \\
\hline
\end{tabular}

tracking speed continually oscillating which leads to smaller peak error jumps than those of the proposed controller. The proposed controller has a good adaptability and robustness to system parameter variations, nonlinear factors, and uncertain disturbances.

\section{Conclusions}

Considering high speed and high precision servo systems with varying inertia and load torque, the characteristic model of the system is established based on the characteristic modeling method, and parameters of the model are obtained by online identification. Considering the good dynamic performance of the second-order sliding mode controller, a discrete second-order sliding mode controller is designed based on characteristic model, and a command observer is also proposed to predict the command value of the next sample time which is used in the controller. The convergence of the observer and closed-loop stability of the system are proved. The experimental results show that the proposed controller can give better tracking performance with varying load torque and inertia compared with typical SMC controller and has better adaptability and robustness.

\section{Conflict of Interests}

The authors declare that there is no conflict of interests regarding the publication of this paper. 


\section{Acknowledgments}

This work was supported by the National Natural Science Foundation of China under Grant no. 61074023, Science and Technology Support Program of Jiangsu Province under Grant no. BE2012175, and “333 Project” Foundation of Jiangsu Province under Grant no. BRA2012163.

\section{References}

[1] M. Nordin and P.-O. Gutman, "Controlling mechanical systems with backlash-a survey," Automatica, vol. 38, no. 10, pp. 16331649, 2002.

[2] B. A. Bucci, J. S. Vipperman, D. G. Cole, and S. J. Ludwick, "Evaluation of a servo settling algorithm," Precision Engineering, vol. 37, no. 1, pp. 10-22, 2013.

[3] C. C. de Wit, H. Olsson, K. J. Astrom, and P. Lischinsky, "A new model for control of systems with friction," IEEE Transactions on Automatic Control, vol. 40, no. 3, pp. 419-425, 1995.

[4] K. Menon and K. Krishnamurthy, "Control of low velocity friction and gear backlash in a machine tool feed drive system," Mechatronics, vol. 9, no. 1, pp. 33-52, 1999.

[5] S. Suraneni, I. N. Kar, O. V. Ramana Murthy, and R. K. P. Bhatt, "Adaptive stick-slip friction and backlash compensation using dynamic fuzzy logic system," Applied Soft Computing Journal, vol. 6, no. 1, pp. 26-37, 2005.

[6] R. H. Du, Y. F. Wu, W. Chen, and Q. Chen, "Adaptive fuzzy speed control for permanent magnet synchronous motor servo systems," Electric Power Components and Systems, vol. 42, no. 8, pp. 798-807, 2014.

[7] J. Liu, Sliding Mode Control Design and Matlab Simulation, Tsinghua University Press, Beijing, China, 2012.

[8] L. Arie, "Quasi-continuous high-order sliding-mode controllers," IEEE Transactions on Automatic Control, vol. 50, no. 11, pp. 1812-1816, 2005.

[9] S. Laghrouche, F. Plestan, and A. Glumineau, "Higher-order sliding mode control based on integral sliding mode," Automatica, vol. 43, no. 3, pp. 531-537, 2007.

[10] J. Chen, Z.-P. Li, and G.-Z. Zhang, "Higher-order sliding-mode controller for a class of uncertain nonlinear systems," Control Theory and Applications, vol. 27, no. 5, pp. 563-569, 2010.

[11] M. Pu, Q.-X. Wu, C.-S. Jiang, and L. Cheng, "Adaptive second-order dynamic sliding-mode control based on fuzzy disturbance-observer," Control Theory and Applications, vol. 28, no. 6, pp. 805-812, 2011.

[12] J.-F. Zheng, Y. Feng, and Q.-L. Lu, "High-order terminal slidingmode control for permanent magnet synchronous motor," Control Theory and Applications, vol. 26, no. 6, pp. 697-700, 2009.

[13] Y.-X. Wu and Y.-M. Hu, "Second order dynamical sliding mode control and its application to output tracking of mobile manipulators," Control Theory and Applications, vol. 23, no. 3, pp. 411-420, 2006.

[14] Z. Lin, G.-R. Duan, and S.-M. Song, "Rigid spacecraft attitude tracking maneuver control based on second-order sliding mode," Systems Engineering and Electronics, vol. 32, no. 2, pp. 346-350, 2010.

[15] M. Mihoub, A. S. Nouri, and R. B. Abdennour, "Real-time application of discrete second order sliding mode control to a chemical reactor," Control Engineering Practice, vol. 17, no. 9, pp. 1089-1095, 2009.
[16] H. Wu, J. Hu, and Y. Xie, "Characteristic model-based allcoefficient adaptive control method and its applications," IEEE Transactions on Systems, Man and Cybernetics Part C: Applications and Reviews, vol. 37, no. 2, pp. 213-221, 2007.

[17] $\mathrm{H}$. Wu, J. Hu, and Y. Xie, Characteristic Model-Based Intelligent Adaptive Control, Chinese Science and Technology Press, Beijing, China, 2008.

[18] R. Merzouki, J. A. Davila, L. Fridman, and J. C. Cadiou, "Backlash phenomenon observation and identification in electromechanical system," Control Engineering Practice, vol. 15, no. 4, pp. 447-457, 2007.

[19] B. Armstrong-Hélouvry, P. Dupont, and C. C. De Wit, "A survey of models, analysis tools and compensation methods for the control of machines with friction," Automatica, vol. 30, no. 7, pp. 1083-1138, 1994. 

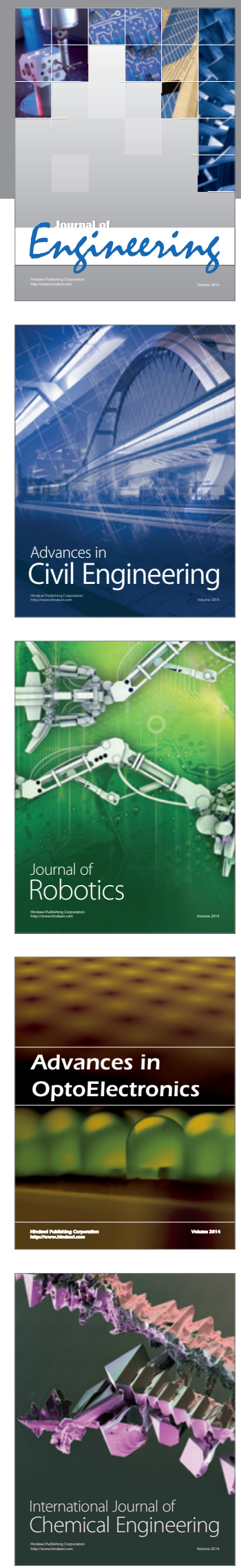

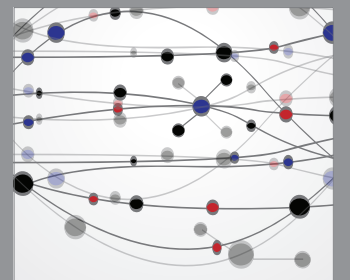

The Scientific World Journal
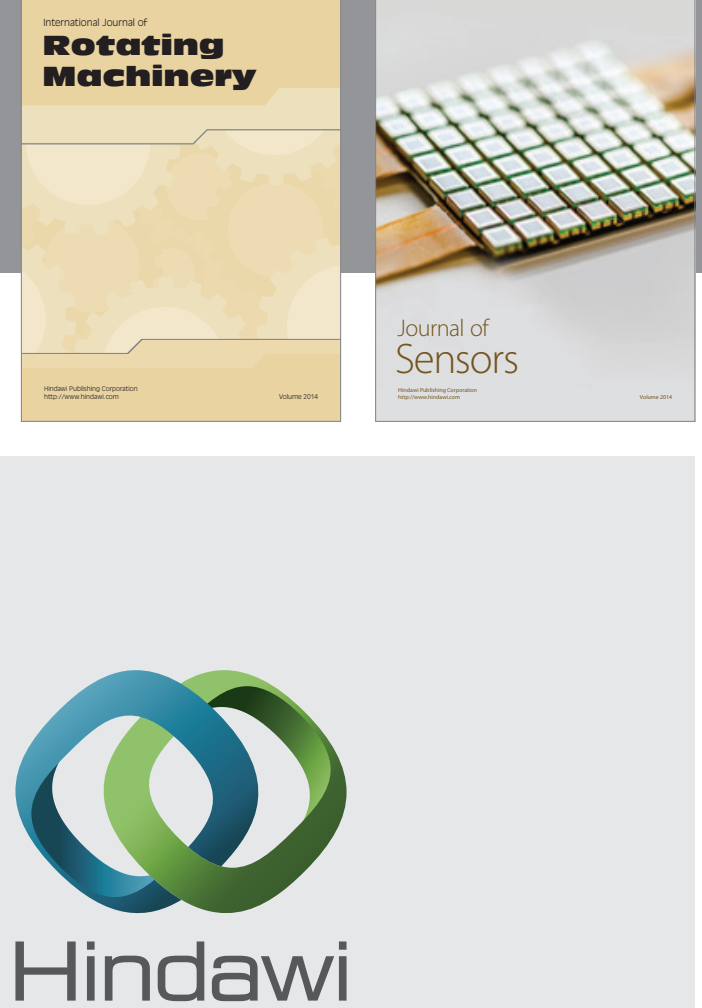

Submit your manuscripts at http://www.hindawi.com
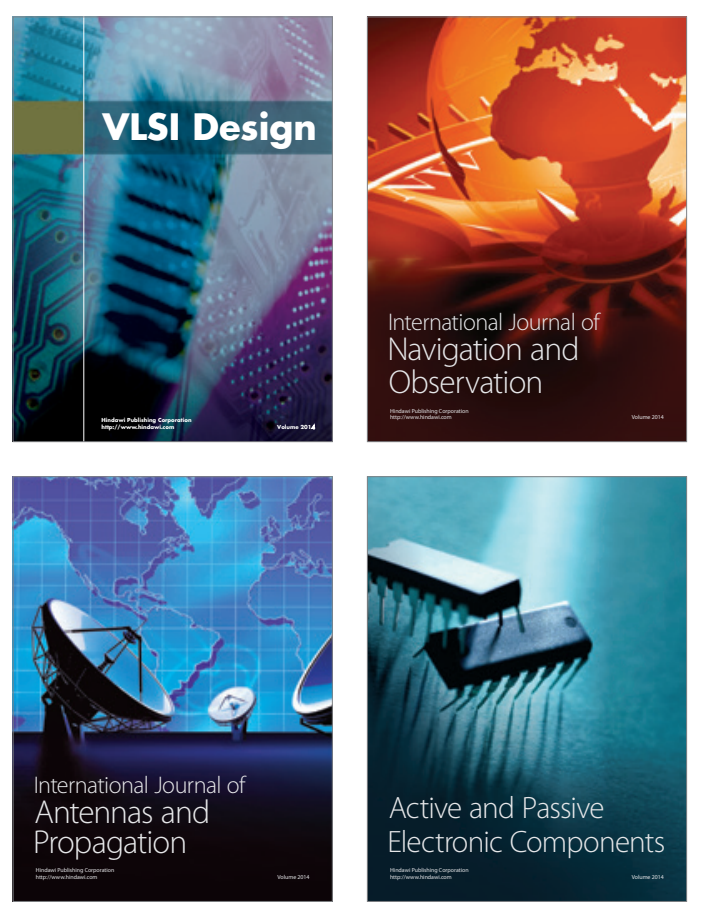
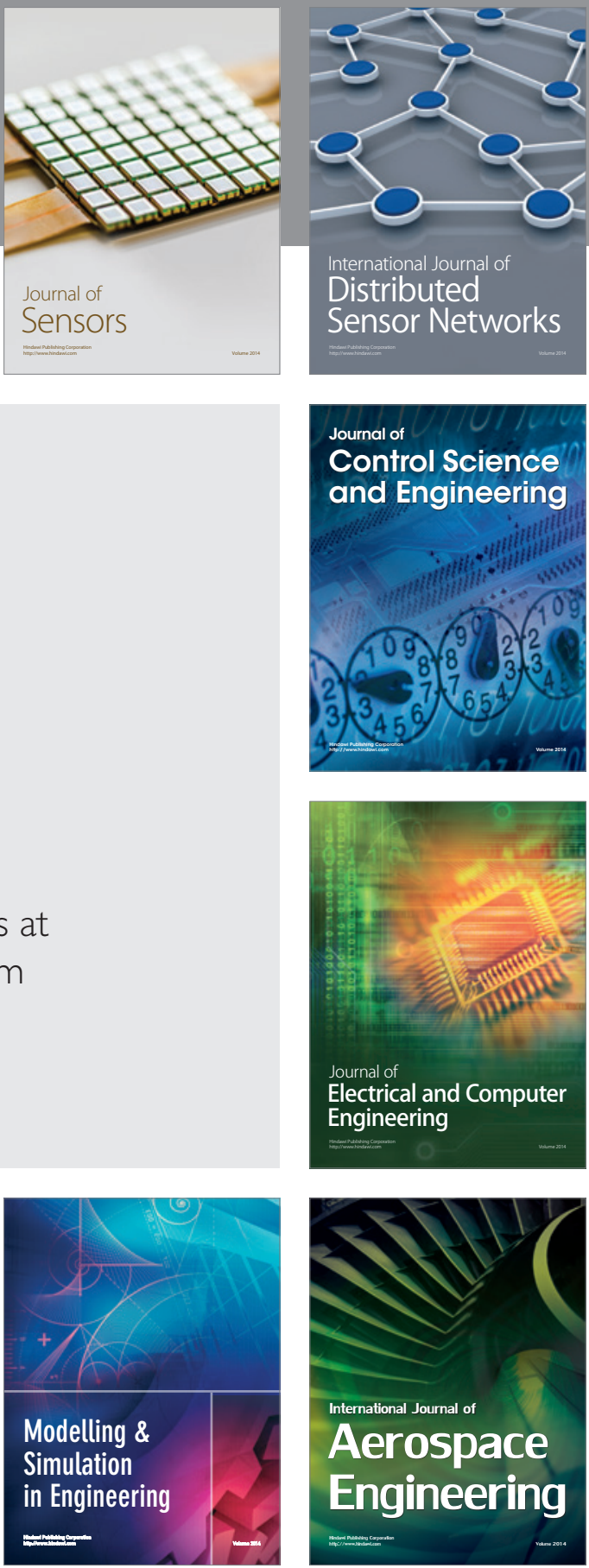

Journal of

Control Science

and Engineering
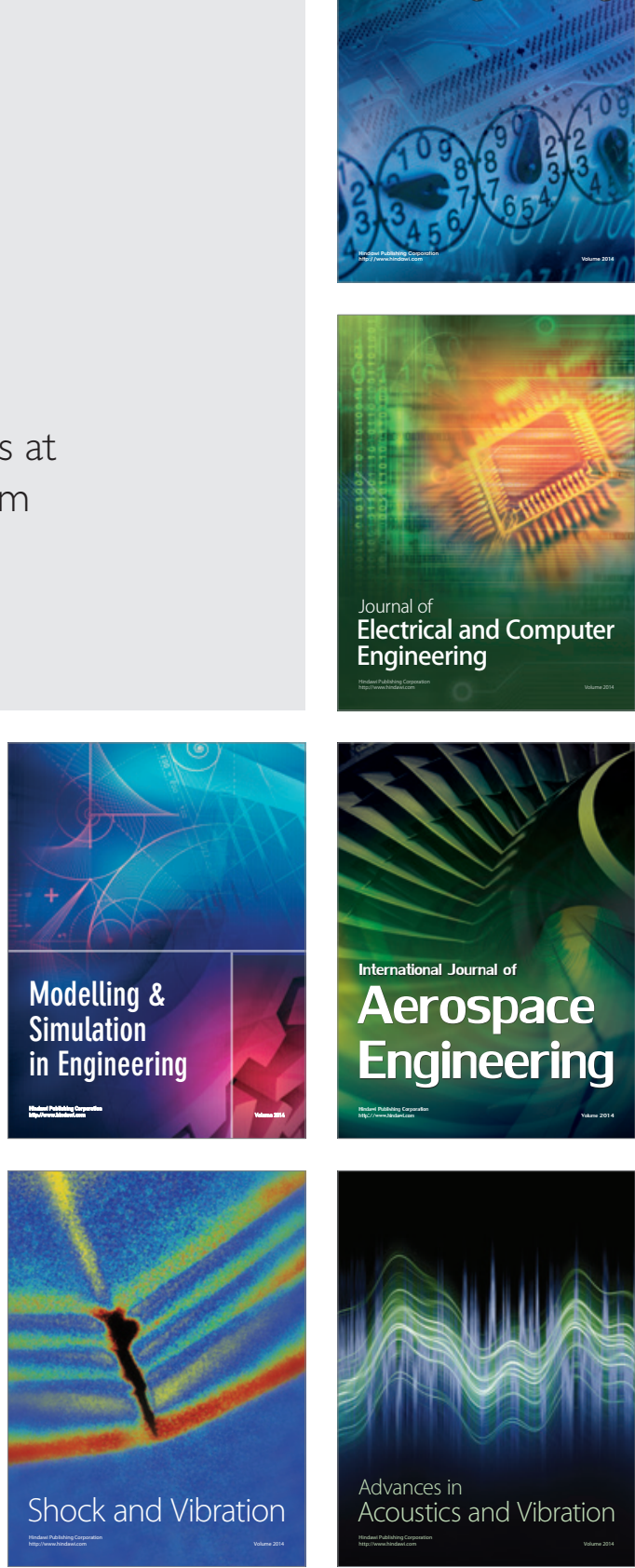